\title{
Pseudomonas chlororaphis PA23 metabolites protect against protozoan grazing by the predator Acanthamoeba castellanii
}

\author{
Akrm Ghergab $^{1}$, Carrie Selin ${ }^{1}$, Jennifer Tanner ${ }^{2}$, Ann Karen Brassinga ${ }^{1}$, Teresa Dekievit ${ }^{\text {Corresp. } 1}$ \\ 1 Department of Microbiology, University of Manitoba, Winnipeg, Manitoba, Canada \\ 2 National Microbiology Laboratory, Public Health Agency of Canada, Winnipeg, Manitoba, Canada \\ Corresponding Author: Teresa Dekievit \\ Email address: teresa.dekievit@umanitoba.ca
}

Background. Pseudomonas chlororaphis strain PA23 is a biocontrol agent that is able to protect canola against the pathogenic fungus Sclerotinia sclerotiorum. This bacterium secretes a number of metabolites that contribute to fungal antagonism, including pyrrolnitrin (PRN), phenazine (PHZ), hydrogen cyanide (HCN) and degradative enzymes. In order to be successful, a biocontrol agent must be able to persist in the environment and avoid the threat of grazing predators. The focus of the current study was to investigate whether PA23 is able to resist grazing by the protozoan predator Acanthamoeba castellanii (Ac) and to define the role of bacterial metabolites in the PA23-Ac interaction.

Methods. Ac was co-cultured with PA23 WT and a panel of derivative strains for a period of 15 days, and bacteria and amoebae were enumerated on days 1, 5, 10 and 15 . Ac was subsequently incubated in the presence of purified PRN, PHZ, and KCN and viability was assessed at 24, 48 and $72 \mathrm{~h}$. Chemotactic assays were conducted to assess whether PA23 compounds exhibit repellent or attractant properties towards Ac. Finally, PA23 grown in the presence and absence of amoebae was subject to phenotypic characterization and gene expression analyses.

Results. PRN, PHZ and HCN were found to contribute to PA23 toxicity towards Ac trophozoites, either by killing or inducing cyst formation. This is the first report of PHZ-mediated toxicity towards amoebae. In chemotaxis assays, amoebae preferentially migrated towards regulatory mutants devoid of extracellular metabolite production as well as a PRN mutant, indicating this antibiotic has repellent properties. Coculturing of bacteria with amoebae led to elevated expression of the PA23 phzl/phzR quorum-sensing (QS) genes and phzA and prnA, which are under QS control. PHZ and PRN levels were similarly increased in Ac co-cultures, suggesting that PA23 can respond to predator cues and upregulate expression of toxins accordingly.

Conclusions. PA23 compounds including PRN, PHZ and HCN exhibited both toxic and repellent effects on Ac. Co-culturing of bacteria and amoebae lead to changes in bacterial gene expression and secondary metabolite production, suggesting that PA23 can sense the presence of these would-be predators and adjust its physiology in response. 

grazing by the predator Acanthamoeba castellanii

5

Akrm Ghergab ${ }^{1}$, Carrie Selin ${ }^{1}$, Jennifer R. Tanner ${ }^{2}$, Ann Karen C. Brassinga ${ }^{1}$ and Teresa de Kievit $^{{ }^{*}}$

${ }^{1}$ Department of Microbiology, University of Manitoba, Winnipeg, MB R3T 2N2, Canada

${ }^{2}$ National Microbiology Laboratory, Public Health Agency of Canada, Winnipeg, MB R3E 3P6, 11 Canada

Running title: PA23 metabolites protect against Acanthamoeba castellani.

*Correspondence: Teresa.dekievit@umanitoba.ca

Tel.: +1-204-474-8987 
27 ABSTRACT

28 Background. Pseudomonas chlororaphis strain PA23 is a biocontrol agent that is able to protect canola against the pathogenic fungus Sclerotinia sclerotiorum. This bacterium secretes a number of metabolites that contribute to fungal antagonism, including pyrrolnitrin (PRN), phenazine (PHZ), hydrogen cyanide ( $\mathrm{HCN})$ and degradative enzymes. In order to be successful, a biocontrol agent must be able to persist in the environment and avoid the threat of grazing predators. The focus of the current study was to investigate whether PA23 is able to resist grazing by the protozoan predator Acanthamoeba castellanii (Ac) and to define the role of bacterial metabolites in the PA23-Ac interaction.

Methods. Ac was co-cultured with PA23 WT and a panel of derivative strains for a period of 15 days, and bacteria and amoebae were enumerated on days 1, 5, 10 and 15. Ac was subsequently incubated in the presence of purified PRN, PHZ, and KCN and viability was assessed at 24, 48 and $72 \mathrm{~h}$. Chemotactic assays were conducted to assess whether PA23 compounds exhibit repellent or attractant properties towards Ac. Finally, PA23 grown in the presence and absence of amoebae was subject to phenotypic characterization and gene expression analyses.

Results. PRN, PHZ and HCN were found to contribute to PA23 toxicity towards Ac trophozoites, either by killing or inducing cyst formation. This is the first report of PHZmediated toxicity towards amoebae. In chemotaxis assays, amoebae preferentially migrated towards regulatory mutants devoid of extracellular metabolite production as well as a PRN mutant, indicating this antibiotic has repellent properties. Co-culturing of bacteria with amoebae

47 led to elevated expression of the PA23 phzI/phzR quorum-sensing (QS) genes and phzA and prnA, which are under QS control. PHZ and PRN levels were similarly increased in Ac co- 
49 cultures, suggesting that PA23 can respond to predator cues and upregulate expression of toxins

50 accordingly.

51 Conclusions. PA23 compounds including PRN, PHZ and HCN exhibited both toxic and

52 repellent effects on Ac. Co-culturing of bacteria and amoebae lead to changes in bacterial gene

53 expression and secondary metabolite production, suggesting that PA23 can sense the presence of

54 these would-be predators and adjust its physiology in response.

\section{INTRODUCTION}

Pseudomonas chlororaphis strain PA23 is a biocontrol agent capable of suppressing

contribute to fungal antagonism. Secreted compounds include the diffusible antibiotics phenazine $(\mathrm{PHZ})$ and pyrrolnitrin $(\mathrm{PRN})$ together with hydrogen cyanide $(\mathrm{HCN})$, protease, chitinase, and lipase (Poritsanos et al., 2006; Zhang et al., 2006). Mutants deficient in either PRN or HCN production exhibit reduced fungal inhibition, indicating that these two products are important for PA23 biocontrol (Selin et al., 2010; Nandi et al., 2017). While PHZ plays a more minor role in pathogen suppression, it does contribute to biofilm formation by this bacterium (Selin et al., 2010). A complex regulatory network that functions at the transcriptional and posttranscriptional level governs expression of these metabolites. For example the GacS-GacA twocomponent system, which works in concert with a second network called Rsm, acts as a positive regulator of PA23 biocontrol (Poritsanos et al., 2006; Selin et al., 2014). Similarly, the PhzRI quorum-sensing (QS) system activates expression of biocontrol genes; while RpoS and the sigma 
71 regulator PsrA function as repressors through downregulation of PRN biosynthetic genes

72 (Manuel et al., 2012; Selin et al., 2012, 2014).

73

74

75

76

77

78

Beyond its ability to suppress the disease-causing pathogen, the success of a biocontrol agent is contingent upon successful colonization of a given environment. One of the primary threats to environmental persistence is consumption by microfaunal predators, including protozoa and nematodes that feed upon bacteria. In response, bacteria have evolved strategies to help resist predation. One such antipredator defence tactic is the production of compounds with toxic and or repellent activities (Ekelund \& Ronn, 1994; Jousset, 2012; Philippot et al., 2013). We have previously demonstrated that PRN and HCN produced by PA23 exhibit nematocidal and repellent activities towards the nematode Caenorhabditis elegans (Nandi et al., 2015). Moreover, co-culturing leads to increased expression of genes and products associated with biocontrol, indicating that PA23 is able to sense and respond to the presence of C. elegans (Nandi et al., 2015).

In the soil, naked amoebae are key drivers of microbial community structure and activity due to their ability to access small pores (Ekelund \& Ronn, 1994). Acanthamoeba castellani (Ac) has been used as a model organism to explore bacteria-amoebae interactions. The life cycle of Ac is comprised of two stages: a vegetative trophozoite and a dormant cyst form. Trophozoites are covered with spindle-like surface projections known as acanthopodia, which are believed to facilitate prey capture, adhesion to surfaces, and cell motility. Under harsh conditions, trophozoites can differentiate into non-dividing, highly resistant cysts (Khan, 2006; MarcianoCabrabal \& Cabral, 2003).

To date, the fate of strain PA23 in the presence of the grazing predator Ac has yet to be explored. The focus of the current study was to ascertain whether PA23 is able to persist in the 
94 presence of this amoeba and to define the role of exoproducts in the predator-prey interaction.

95 Our findings revealed that PRN, PHZ and HCN have detrimental effects on trophozoite viability

96 and therefore help to protect against protozoan grazing in vitro. Co-culturing with amoebae led

97 to enhanced expression of secondary metabolite genes and products, suggesting that PA23 is able

98 to detect the presence of amoebae and adjust its physiology accordingly.

\section{MATERIALS AND METHODS}

101

\section{Bacterial strains and growth conditions}

102 All bacterial strains and plasmids used in this study are listed in Table 1. Escherichia coli was cultured at $37^{\circ} \mathrm{C}$ on Lysogeny Broth (LB) agar (Difco Laboratories, Detroit, MI, USA). $P$. chlororaphis strains were routinely cultured on LB or in M9 minimal salts medium supplemented with $0.2 \%$ glucose and $1 \mathrm{mM}$ magnesium sulphate $\left(\mathrm{M} 9\right.$-glc) at $28^{\circ} \mathrm{C}$. Media was supplemented with the following antibiotics: ampicillin (Amp; $100 \mu \mathrm{g} / \mathrm{ml})$, gentamicin (Gm; 15 $\mu \mathrm{g} / \mathrm{ml}$ ) for $E$. coli, and piperacillin (Pip; $40 \mu \mathrm{g} / \mathrm{ml})$, Gm $(20 \mu \mathrm{g} / \mathrm{ml})$, tetracycline (Tc; $15 \mu \mathrm{g} / \mathrm{ml})$ for PA23. All antibiotics were obtained from Research Products International Corp. (Mt.

Prospect, IL, USA).

Acanthamoeba strain and culture conditions

Acanthamoeba castellanii (ATCC 30234) was grown axenically without shaking in $20 \mathrm{ml}$ of

PYG medium (proteose peptone $10 \mathrm{~g} / \mathrm{L}$, yeast extract $5 \mathrm{~g} / \mathrm{L}$, glucose $10 \mathrm{~g} / \mathrm{L}$ and the additives: 4 $\mathrm{mM} \mathrm{MgSO}_{4} \cdot 7 \mathrm{H}_{2} \mathrm{O}, 0.4 \mathrm{mM} \mathrm{CaCl}_{2}, 0.05 \mathrm{mM} \mathrm{Fe}\left(\mathrm{NH}_{4}\right) 2\left(\mathrm{SO}_{4}\right) 2 \cdot 6 \mathrm{H}_{2} \mathrm{O}, 2.5 \mathrm{mM} \mathrm{Na}_{2} \mathrm{HPO}_{4} \bullet 7 \mathrm{H}_{2} \mathrm{O}$,

116 (Sarstedt, Saint-Leonard, QC, Canada) in a humidified incubator at $25{ }^{\circ} \mathrm{C}$. Before the 
117 experiment, cultures were washed three times with Ac buffer (PYG medium lacking proteose

118 peptone, yeast extract and glucose) (Moffat \& Tompkins, 1992) to remove non-adherent cells or

119 any existed cysts. Amoeba trophozoite density was measured using a Neubauer cell counting

120 chamber. To obtain amoeba cell-free supernatant, cells were grown in Ac buffer for three days at

$12125^{\circ} \mathrm{C}$ and then filtered using $0.22 \mu \mathrm{m}$ filters (Sarstedt). Supernatants were stored at $-80{ }^{\circ} \mathrm{C}$.

122

123 P. chlororaphis PA23 - Ac co-culture assays

124 To study amoeba-bacterial interactions, Ac trophozoites were washed three times with Ac buffer.

125 Amoebae were adjusted to $10^{6}$ cells $/ \mathrm{ml}$, and 1-ml aliquots were transferred into wells of a $24-$

126 well plate and incubated at $28^{\circ} \mathrm{C}$ for $1 \mathrm{~h}$ to allow adherence. Wells were washed three times with

127 Ac buffer to remove non-adherent amoebae. Next, bacterial suspensions grown in M9-glc were

128 washed twice with M9-glc and adjusted to $10^{8} \mathrm{CFU} / \mathrm{ml}$. A 1-ml volume of bacteria was added to

129 each well and allowed to incubate at $28^{\circ} \mathrm{C}$ for 15 days. Growth and viability of amoeba

130 trophozoites was determined by microscopic visualization of eosin-stained cells (dead cells stain

131 red; live cells remain unstained; cysts are morphologically distinct) following the method

132 Neilson et al., (1978). Briefly, a $10-\mu 1$ volume of a $0.5 \%(\mathrm{v} / \mathrm{v})$ basic eosin solution was added to

133 a $10-\mu 1$ volume of Ac trophozoites grown in the presence and absence of bacteria. Ac cells were

134 examined and enumerated with a Neubauer cell counting chamber. The number of extracellular

135 bacteria residing in the co-culture samples was determined through viable plate counting.

136 Amoebae grown in the absence of bacteria were used as a negative control. Experiments were 137 repeated three times. 


\section{Effect of secondary metabolites on Ac trophozoite viability}

140 Cultures of PA23 strains were incubated for 3 days at $28^{\circ} \mathrm{C}$, and then cells were pelleted, and the

141 supernatant passed through a $0.2-\mu \mathrm{m}$ filter to remove all bacterial cells. The experiment setup

142 was the same as described above, except that bacterial supernatant was added to the wells. The

143 morphological changes of amoeba were monitored using an inverted microscope (Zeiss Observer

144 Z1 inverted microscope, Carl Zeiss Microscopy GmbH, Göttingen, Germany). To determine the

145 effect of purified compounds on Ac, amoebae were adjusted to $10^{6}$ cells $/ \mathrm{ml}$ in Ac buffer

146 containing commercially purified PRN (Sigma, St. Louis, MO, USA) at the following

147 concentrations: $0 \mu \mathrm{g} / \mathrm{ml}$ (control), $0.1,0.5,1,5$ and $10 \mu \mathrm{g} / \mathrm{ml}$, or KCN (Sigma) at the following

148 concentrations: $0 \mu \mathrm{g} / \mathrm{ml}$ (control), 50, 100, 200, 400 and $800 \mu \mathrm{g} / \mathrm{ml}$. For PHZ analysis, a 15-ml

149 overnight culture of PA23-PRN ${ }^{-}$grown in LB medium was used to extract PHZ following the

150 method of Selin et al. (2010). In brief, PHZ extractions were quantified with UV-visible

151 spectroscopy (Biochrom Ltd. Cambridge, England), and the absorption maxima for PCA and 2-

$152 \mathrm{OH}-\mathrm{PHZ}$ were measured at 367 and $490 \mathrm{~nm}$, respectively. Amoeba cells were incubated with

153 extracted PHZ at the following concentrations: 0, 10, 20, 35, and $50 \mu \mathrm{g} / \mathrm{ml}$. Ac subcultures

154 containing various concentrations of PRN, PHZ and KCN were incubated in 24-well plates at 28

$155{ }^{\circ} \mathrm{C}$, and amoeba viability was monitored at 1, 6, 12, 18, 24, 48 and $72 \mathrm{~h}$. Five replicates were

156 included per assay, and the experiment was repeated three times.

157

158 Chemotaxis assays

159 Bacteria were grown in M9-glc medium at $28^{\circ} \mathrm{C}$ for $24 \mathrm{~h}$. Axenically grown Ac cultures were

160 prepared as described above. Petri dishes $(60 \times 15 \mathrm{~mm})$ containing $5 \mathrm{ml}$ of $1.5 \%$ water agar had

161 three wells created $20 \mathrm{~mm}$ apart. An aliquot of $50 \mu \mathrm{l}$ of Ac $\left(10^{6}\right.$ cells $\left./ \mathrm{ml}\right)$ was transferred into 
162 the centre well. One of the two outside wells contained $50 \mu$ l of "test" bacterial inoculum, while

163 the second well contained a $50 \mu 1$ suspension of PA23 WT, the gacS mutant, or saline as the

164 "control" sample. A hand-crafted grid coverslip was placed underneath the plate for counting

165 amoebae that had migrated from the centre well towards the outside wells moving under the

166 agar. The chemotactic index was calculated based on the formula: number of amoebae migrating

167 towards the test sample/number of amoebae moving towards the control sample. Experiments

168 wherein the test and control wells contained the same sample, namely saline and PA23 WT were

169 used to demonstrate equal attraction as a means of calibrating the test. Experiments were

170 repeated three times.

171

172 Analysis of transcriptional fusions in the presence and absence of Ac

173 The activity of $p r n A$-, $p h z A$-, $p h z I-, p h z R$-, rpoS-, and gacS-lacZ transcriptional fusions was

174 determined in PA23 cultured in the presence and absence of Ac trophozoites. Active amoebae

175 were adjusted to $10^{6}$ cells/ml in Ac buffer, as described above. Overnight bacterial cultures

176 grown in M9-glc were adjusted to an optical density of $0.1\left(2 \times 10^{8} \mathrm{CFU} / \mathrm{ml}\right)$ prior to co-culture

177 with Ac or amoeba-free supernatant. Samples were grown for 24, 48, and $72 \mathrm{~h}$ in M9-glc at

$17828^{\circ} \mathrm{C}$. The effect of Ac cells or cell-free supernatant on PA23 gene activity was determined by $\beta$ -

179 galactosidase assays (Miller, 1972) and experiments were repeated three times.

180

\section{Antifungal activity}

182 To assess the ability of PA23 and derivative strains to inhibit the growth of S. sclerotiorum in

183 vitro, radial diffusion assays were performed as described by Poritsanos et al. (2006). Bacteria 
184 were grown in M9-glc in the presence and absence of trophozoites for $72 \mathrm{~h}$ at $28^{\circ} \mathrm{C}$. Five

185 replicates were analyzed for each strain and experiments were repeated three times.

186 Autoinducer detection assay

187 AHL analysis was conducted by spotting a 5- $\mu \mathrm{L}$ aliquot of cultures onto LB agar seeded with $C$.

188 violaceum CV026. Strain CV026 is able to detect exogenous AHLs with carbon chain lengths

189 ranging from $\mathrm{C} 4-\mathrm{C} 8$, resulting in a deep purple halo surrounding the bacterial colony(Latifi et

190 al., 1995). The diameter of purple pigment surrounding the bacterial colonies was measured

191 (Poritsanos et al., 2006). Five replicates were analysed for each strain, and the experiment was

192 repeated three times.

193

194 Protease analysis

195 Extracellular protease production was determined qualitatively by inoculating a 5- $\mu \mathrm{L}$ volume of 196 bacterial culture onto a $1.5 \%$ agar plate containing $2 \%$ skim milk (Difco). Protease activity was 197 indicated by a zone of lysis surrounding the colony after $36-48 \mathrm{~h}$ growth at $28^{\circ} \mathrm{C}$ (Poritsanos et al., 2006). Zones of clearing were measured for each strain. Data represent the average of five replicates, and the experiment was repeated three times.

200

201

\section{Motility analysis}

202

To assess the impact of amoebae on PA23 flagellar (swimming) motility, bacteria were grown overnight in M9-glc in the presence and absence of trophozoites. A 5- $\mu$ l volume of culture containing bacteria or bacteria plus Ac were inoculated below the surface of a $0.3 \% \mathrm{LB}$ agar plate (Poritsanos et al., 2006). The plates were incubated at $28^{\circ} \mathrm{C}$ and the swim zone diameter 
206 was measured at 24, 48 and $72 \mathrm{~h}$. For the assays, five replicates were analyzed, and the 207 experiment was repeated three times. 


\section{Quantitative analysis of PRN and PHZ}

210 Production of PRN was quantified by HPLC as described by Selin et al. (2010) with the

211 following modifications. PA23 cultures started at an initial concentration of $10^{8} \mathrm{CFU} / \mathrm{ml}$ were

212 grown in the presence and absence of the amoeba $\left(10^{6}\right.$ cells $\left./ \mathrm{ml}\right)$ at $28^{\circ} \mathrm{C}$ in $30 \mathrm{ml} \mathrm{M9-glc.} \mathrm{PRN}$

213 was extracted and quantified after $96 \mathrm{~h}$. Toluene was added to the culture supernatants as an

214 internal control. Peaks corresponding to the toluene and PRN were analyzed by UV absorption at

$215225 \mathrm{~nm}$ using a Varian 335 diode array detector. For analysis of PHZ production, PA23 cultures

$216\left(10^{8} \mathrm{CFU} / \mathrm{ml}\right)$, were grown in the presence and absence of Ac $\left(10^{6}\right.$ cells $\left./ \mathrm{ml}\right)$ in $30 \mathrm{ml} \mathrm{M9-glc} \mathrm{at}$

$21728^{\circ} \mathrm{C}$ for $72 \mathrm{~h}$. PHZ was quantified according to the method of Selin et al. (2010) as described

218 above. PRN and PHZ analysis was performed in triplicate and experiments were repeated twice.

\section{Statistical analysis}

An unpaired Student's t test was used for statistical analysis of PRN, PHZ, AHL production, swimming motility, AF activity and protease production. The Tukey test was applied to determine the chemotactic preference of amoebae for each of the bacterial strains. The two-way ANOVA test was applied for amoeba-bacterial co-culture assays and gene expression analysis.

\section{RESULTS}

\section{PA23 affects Ac trophozoite viability}

To determine the impact of PA23 on Ac trophozoite viability and cyst formation, the

PA23 WT and derivative strains, including regulatory (rpoS $S^{-}, g a c S^{-}, p h z R^{-}$and AI-deficient) and biosynthetic mutants (PRN-, PHZ-, and $\left.\mathrm{HCN}^{-}\right)$were offered as prey. Previous phenotypic 
232 degradative enzymes (Poritsanos et al., 2006; Selin et al., 2012). As illustrated in Figure 1, in the 233 presence of the $g a c S^{-}, p h z R^{-}$, and AI-deficient strains, Ac trophozoite numbers increased on days

2341 and 5, after which the amoebae remained active but the population declined slowly. When co-

235 incubated with PA23 WT, PHZ, $\mathrm{PRN}^{-}, \mathrm{HCN}^{-}$and $r p o S^{-}$cells, the number of trophozoites

236 steadily decreased over time (Fig. 1). Supplemental Figure 1 depicts the proportion of viable,

237 encysted and dead Ac at each time point. At day 15, there were less trophozoites present in co-

238 cultures with the PHZ- strain, compared to PA23 WT. We have previously demonstrated that this

239 bacterium and the rpoS mutant secrete increased levels of PRN relative to WT (Manuel et al.,

240 2012; Selin et al., 2010). Conversely, trophozoite numbers were significantly elevated when

241 grown on the $\mathrm{PRN}^{-}$and $\mathrm{HCN}^{-}$strains compared to those grown on the PHZ- strain at day 15 (Fig.

242 1). Collectively, these results indicate that PA23 exoproducts play a role in the inhibition of Ac 243 growth.

\section{Bacterial persistence upon co-culturing with Ac trophozoites}

To investigate whether bacterial growth was affected by the presence of amoebae,

bacteria were co-cultured with Ac and viability was assessed over time. The number of PA23

WT, rpoS $S^{-}$and PHZ- cells increased from $10^{8} \mathrm{CFU} / \mathrm{ml}$ on day 0 to between $9.7 \times 10^{8}$ and $9.8 \times 10^{8}$

$\mathrm{CFU} / \mathrm{ml}$ on day 1 (Fig. 2). The $\mathrm{HCN}^{-}$and $\mathrm{PRN}^{-}$strains also increased from $10^{8} \mathrm{CFU} / \mathrm{ml}$ to 7.5 
255 dramatically reduced. Bacteria populations continued to decrease by day 10, with the largest

256 number of cells remaining for the PA23 WT, PHZ- and $r p o S^{-}$strains (Fig. 2). There were no

257 viable cells recovered on day 15 (data not shown). In the absence of Ac, there were no

258 observable differences in bacterial viability between strains over time (Supplemental Figure 2).

259

260

\section{The effect of PA23 metabolites on Ac viability}

To further explore the impact of PA23 exoproducts on Ac trophozoites, amoebae were challenged with cell-free supernatant from the PA23 WT and the gacS mutant (Fig. 3). After $1 \mathrm{~h}$ incubation with WT supernatant, amoeba cells started to swell and this continued until they began to burst at $2 \mathrm{~h}$ (Fig. 3a). Conversely, incubation with gac $^{-}$supernatant did not affect amoeba morphology (Fig. 3b). Next, we investigated how feeding on nontoxic bacteria in the presence of antifungal (AF) metabolites impacts amoebae. Ac trophozoites were co-cultured with GFP-tagged gacS- mutant cells resuspended in PA23 cell-free supernatant. As depicted in Figure $3 \mathrm{c}$, at $1 \mathrm{~h}$, amoebae had lost their amoebic shape. After $2 \mathrm{~h}$ incubation, trophozoites were fluorescing green consistent with uptake of the gac $^{-}$cells. Despite the fact that the trophozoites were actively feeding, they underwent the same morphological changes as when challenged with PA23 WT supernatant alone (Fig. 3a), including cell lysis (Fig. 3c). Collectively these finding indicate that secreted PA23 metabolites exert deleterious effects on Ac trophozoites. were challenged with PRN $(0-10 \mu \mathrm{g} / \mathrm{ml}), \operatorname{PHZ}(0-50 \mu \mathrm{g} / \mathrm{ml})$ and $\mathrm{KCN}(0-800 \mu \mathrm{g} / \mathrm{ml})$. As illustrated in Figure 4a, when exposed to PRN at a concentration of $1 \mu \mathrm{g} / \mathrm{ml}$ or lower, there was no impact on amoeba viability. However at higher PRN levels, the number of Ac trophozoites

277 declined in a dose-dependent fashion (Fig. 4a). PHZ was also found to exhibit toxic effects on 
278 the amoebae. Exposure to $\leq 20 \mu \mathrm{g} / \mathrm{ml} \mathrm{PHZ} \mathrm{had} \mathrm{little} \mathrm{effect} \mathrm{on} \mathrm{protozoan} \mathrm{survival,} \mathrm{but} \mathrm{at} \mathrm{higher}$

279 concentrations $(35-50 \mu \mathrm{g} / \mathrm{ml})$, amoeba viability decreased to less than $50 \%$ after $24 \mathrm{~h}$ (Fig. $4 \mathrm{~b}$ ).

280 Exposure to KCN led to a reduction in the number of Ac trophozoite at concentrations of 400

$281 \mu \mathrm{g} / \mathrm{ml}$ and above (Fig. 4c).

282

283 PA23 exoproducts affect the chemotactic response of Ac

Bacterial metabolites can exhibit either attractant or repellent effects, and this can

285

286

287

288

289

290

291

292

293

294

295

296

297

298

299

300

301

296

ultimately impact predator grazing. To study the chemotactic response of Ac towards bacteria, binary choice assays were undertaken, as depicted in Figure 5a. Compared to saline control, trophozoites were more attracted to the $g a c S^{-}$, QS-deficient, and $\mathrm{PRN}^{-}$strains, all of which lack PRN production (Fig. 5b). Whereas PA23 WT, and the PRN hyper-producing PHZ- and rpoS mutants exhibited a repellent effect. Amoebae were marginally attracted to the $\mathrm{HCN}^{-}$strain (Fig. 5b). Employing PA23 as the control, amoebae preferentially migrated towards all of the strains except for the PRN overproducers (PHZ- and rpoS- mutants; Fig. 5c). Trophozoites clearly had a strong preference for the $g a c S^{-}$derivative because when it was included as the control, Ac consistently migrated towards this bacterium (Fig. 5d). Once again, the PRN-producers (PHZ; $r p o S^{-}, \mathrm{HCN}^{-}$and PA23 WT) exhibited the strongest repellent activity (Fig. 5d).

\section{Growth in the presence of Ac affects PA23 gene expression}

To determine whether bacteria can sense the presence of the predator, PA23 was grown together with amoebae cells or cell-free supernatants and monitored for changes in gene expression. For this assay, biosynthetic ( $p r n A$ and $p h z A)$ and regulatory genes (phzI, phzR, rpoS, gacS) were analyzed. No changes in gene expression were observed in bacteria incubated with Ac cell-free supernatants. However, co-incubation of PA23 with trophozoites resulted in 
302 elevated expression of $p h z A$ and $p r n A$ at both $48 \mathrm{~h}$ and $72 \mathrm{~h}$ (Fig. 6). For the QS genes $p h z I$ and

$303 p h z R$, co-culturing resulted in a significant increase in phzI-lacZ activity at all time points tested,

304 whereas $p h z R$ activity was elevated at only 48 h (Fig. 6). Growth with trophozoites led to an

305 increase in the $r p o S$-lacZ activity at $72 \mathrm{~h}$, while no change in gacS expression was observed at

306 any of the time points (Fig. 6).

307

308

\section{Impact of Ac on PA23 phenotypic traits}

Phenotypic analysis was undertaken to determine whether changes in secondary

metabolite production or other traits were brought on by growth in the presence of Ac. As

outlined in Table 2, co-incubation with amoebae led to increased PRN and PHZ production, consistent with the elevated $p h z A$ and $p r n A$ gene activity. Other phenotypic traits, including fungal inhibition, protease activity, and swimming motility, were unaffected by Ac (Table 2).

\section{DISCUSSION}

The ability of bacteria to persist in the soil is profoundly affected by grazing predators, including protozoa. In response, bacteria have developed a number of defensive mechanisms to avoid predation, such as toxin production (Jousset, 2012). The current study aimed to investigate the interaction between PA23 and the model protozoan predator Ac. Specifically, we were interested in whether PA23 AF metabolites facilitate survival in the presence of this predator and their impact on Ac viability. Additionally, we explored bacterial survival within vacuoles of trophozoites. 
325

326

327

328

329

330

331

332

333

334

335

336

337

338

339

340

341

342

343

344

345

346

347

mutations in QS and the GacS-GacA two-component system abolished exoproduct formation, which in turn led to a decrease in AF activity (Poritsanos et al., 2006; Selin et al., 2012, 2014).

Our prey-predator co-culture assay revealed that the PA23 WT, and the $\mathrm{PHZ}^{-}$and $r p o S^{-}$mutants caused a dramatic reduction in the number of Ac trophozoites either by transforming into dormant cysts or causing cell death (Fig. 1). PRN production is elevated 2.2-and 1.6-fold in PHZand $r p o S^{-}$backgrounds, respectively (Manuel et al., 2012; Selin et al., 2012). The increased mortality of Ac trophozoites co-cultured with these PRN hyper-producing strains led us to speculate that this antibiotic is involved in PA23 toxicity towards the predator (Fig. 1). When Ac trophozoites were challenged with different concentrations of purified PRN, viable amoebae decreased in a dose-dependent fashion (Fig. 4a). Consistent with these findings, Jousset and coworkers (2010) reported that purified PRN and 2,4-diacylphloroglucinol (DAPG) exhibited toxic effects towards Ac trophozoites causing rapid cell death after $6 \mathrm{~h}$ of incubation. In another study, the antibiotics DAPG, pyoluteorin (PLT) and PRN induced cyst formation in the amoeba Vahlkampfia, while the growth of amoebae was enhanced when co-cultured with toxin-deficient strains (Jousset et al., 2006). The toxicity associated with PRN is not surprising as it is known to affect a wide range of microorganisms, including fungi and protists (Chernin et al., 1996). This compound interferes with cellular processes such as respiratory pathways and osmotic regulation (Okada et al., 2005; Tripathi \& Gottlieb, 1969).

PA23 also produces the volatile compound HCN that plays a role in AF activity (Nandi et al., 2017) and contributes to its nematicidal effects on C. elegans (Nandi et al., 2015). For that reason, we were interested to understand whether $\mathrm{HCN}$ exerts toxic effects on Ac trophozoites. We observed that Ac preferentially consumed the $\mathrm{HCN}^{-}$strain and this bacterium supported slightly higher trophozoite numbers compared to PA23 WT (Fig. $1 \& 2$ ). When amoebae were 
348 incubated with purified $\mathrm{KCN}$, a significant decline in the number of Ac was detected at

349 concentrations of $400 \mu \mathrm{g} / \mathrm{ml}$ and higher (Fig. 4c). HCN is a broad-spectrum toxin that affects a

350 wide range of organisms, such as fungi and nematodes (Blumer \& Haas, 2000) and it also

351 appears to inhibit Ac growth, albeit modestly.

352 PA23 produces two diffusible PHZ compounds, namely phenazine-1-carboxylic acid

353 (PCA) and 2-hydroxyphenazine (2-OH-PHZ) that impart an orange colour to PA23 cells. We

354 have previously demonstrated that PHZ production plays only a minor role in AF activity;

355 however, it contributes to PA23 biofilm formation (Selin et al., 2010). In co-cultures, the PHZ-

356 producing strains (WT, $\left.\mathrm{PRN}^{-}, \mathrm{HCN}^{-}, r p o S^{-}\right)$were less palatable than several of the PHZ-deficient

357 bacteria (gacS, phzR-, AI-deficient) (Fig. 2). The one outlier being the PHZ- mutant that wasn't

358 highly consumed, which is most likely due to the elevated levels of PRN produced by this strain

359 (Selin et al., 2010). PHZ toxicity was further demonstrated by the fact that exposure to this

360 compound resulted in a dose-dependent decrease in Ac viability (Fig. 4b). To the best of our

361 knowledge, this is the first report of PHZ having amoebicidal activity. A study by Matz et al.

362 (2004) reported that the purple pigment violacein produced by Janthinobacterium lividum and

363 Chromobacterium violaceum is acutely toxic for the bacterivorous nanoflagellates Bodp saltans

364 Ochromonas sp. and Spumella sp. Ingestion of WT bacteria induced rapid cell lysis whereas non-

365 pigmented mutants supported protozoan growth. In addition, purified violacein was found to be

366 highly toxic for the flagellates (Matz et al., 2004).

367 Secondary metabolites provide additional benefits if they are able to act as deterrents,

368 allowing bacteria to avoid consumption all together. To investigate whether PA23 exoproducts

369 exhibit repellent or attractant properties, chemotactic response assays were performed. We

370 discovered that amoebae had a strong preference for the toxin-deficient $g a c S^{-}$, phz $R^{-}$, and $\mathrm{AI}^{-}$ 
371 strains (Fig. 5). Moreover, there was very little difference between these three bacteria and the

$372 \mathrm{PRN}^{-}$strain, suggesting that PRN acts as a strong repellent (Fig. 5). We have previously shown

373 that PRN exerts similar effects on C. elegans (Nandi et al., 2015). The HCN- mutant, on the other

374 hand, closely resembled PA23 WT (Fig; 3.6); therefore, HCN does not significantly impact Ac

375 chemotaxis. Because the PHZ- strain produces twice as much PRN as WT, it was not possible to

376 assess whether PHZ affects Ac migration. While we observed only repellent effects, bacterial

377 chemicals can also act as attractants. Gaines and coworkers (2019) reported that the model

378 protozoa Eglena gracilis showed a positive chemotactic response towards Listeria

379 monocytogenes cells. The authors suggested that the small molecules released from $L$.

380

381

382

383

384

385

386

387

388

389

390

391

392

393 monocytogenes such as volatile organic compounds exhibited chemoattractant activity and were responsible for attracting Euglena (Gaines et al., 2019). Collectively, our findings suggest that

Ac trophozoites were able to sense and respond to PA23 chemical cues. Ac was only attracted to toxin-deficient strains; in particular those lacking PRN, suggesting that this antibiotic may facilitate PA23 survival in the soil.

While toxic metabolites are an effective strategy for reducing predator populations, biosynthesis of these compounds is energetically costly for the producer (Jousset, 2012). Clearly, the ability to optimize toxin production according to predation risk is beneficial for bacteria (Steiner, 2007). Therefore, we were interested to determine whether co-culturing with Ac alters expression of PA23 genes and AF products. Increased expression of $p h z A$ and $p r n A$ occurred in the presence of amoebae at $48 \mathrm{~h}$ and $72 \mathrm{~h}$; whereas no change was observed when bacteria were incubated with Ac supernatants. Our PHZ and PRN analysis confirmed elevated production of these antibiotics (Table 2). It is interesting that the $p h z I$ and $p h z R$ QS genes were also upregulated in the presence of Ac, because the Phz QS system positively regulates $\mathrm{phz}$ and $\mathrm{prn}$ 
394 gene expression (Selin et al., 2012). It is not clear at this time whether the effects of Ac on PHZ 395 and PRN production are directly or indirectly mediated. We have previously shown that co396 culturing PA23 with C. elegans led to increased $p r n A$ and $p h z A$ gene expression, while cell-free 397 supernatants had no effect (Nandi et al., 2015). Similarly, Mazzola and coworkers (2009) reported that production of the cyclic lipopeptides massetolide and viscosin by Pseudomonas protegens SS101 and SBW25, respectively, were essential for protecting bacteria from predation by Naegleria americana. Moreover, the authors observed an upregulation of mass ABC

(massetolide) and viscABC (viscosinamide) when bacteria were challenged with protozoa 402 (Mazzola et al., 2009). In contrast to our findings, $P$. protegens $\mathrm{CHA} 0$ grown in the presence of Ac cell-free supernatants exhibited elevated phlA (DAPG) and prnA gene expression and increased DAPG and PRN production. However, direct contact with the predator resulted in a reduction in gene expression (Jousset et al., 2010). Collectively these findings indicate that predators and prey can sense and respond to one another, either through direct contact or soluble 407 chemical cues.

\section{CONCLUSION}

Findings presented herein demonstrate that PRN, PHZ and HCN all contribute to PA23mediated inhibition of Ac in vitro. PA23 is able to sense the presence of amoebae and upregulate expression of genes and antipredator compounds accordingly. We have previously shown that PHZ is not essential for PA23-mediated biocontrol of the plant pathogen S. sclerotiorum but it is involved in biofilm formation. Intriguingly, PHZ also has amoebicidal properties. Taken together, toxins produced by PA23 exhibit broad-spectrum antagonism, not only towards fungal 
416 predators in the rhizosphere using different protists will provide additional insight into PA23

417 persistence in the environment.

418

419 
420

421

422

423

424

425

426

427

428

429

430

431

432

433

434

435

436

437

438

439

440

441

442

443

444

445

446

447

448

449

450

\section{REFERENCES}

Blumer, C., \& Haas, D. (2000). Mechanism, regulation, and ecological role of bacterial cyanide biosynthesis. Archives of Microbiology. 173(3): 170-177.

Bui, X. T., Winding, A., Qvortrup, K., Wolff, A., Bang, D. D., \& Creuzenet, C. (2012). Survival of Campylobacter jejuni in co-culture with Acanthamoeba castellanii: Role of amoeba-mediated depletion of dissolved oxygen. Environmental Microbiology. 14(8): 2034-2047.

Chernin, L., Brandis, A., Ismailov, Z., \& Chet, I. (1996). Pyrrolnitrin production by an Enterobacter agglomerans strain with a broad spectrum of antagonistic activity towards fungal and bacterial phytopathogens. Current Microbiology. 32(4): 208-212.

de Kievit, T. R., Gillis, R., Marx, S., Brown, C., \& Iglewski, B. H. (2001). Quorum-Sensing Genes in Pseudomonas aeruginosa Biofilms: Their Role and Expression Patterns. Applied and Environmental Microbiology. 67(4):1865-1873.

Ekelund, F., \& Rõnn, R. (1994). Notes on protozoa in agricultural soil with emphasis on heterotrophic flagellates and naked amoebae and their ecology. FEMS Microbiology Reviews. 15(4): 321-353.

Fernando, W. G. D., Nakkeeran, S., Zhang, Y., \& Savchuk, S. (2007). Biological control of Sclerotinia sclerotiorum (Lib.) de Bary by Pseudomonas and Bacillus species on canola petals. Crop Protection. 26(2): 100-107.

Gaines, A., Ludovice, M., Xu, J., Zanghi, M., Meinersmann, R. J., Berrang, M., Daley, W., \& Britton, D. (2019). The dialogue between protozoa and bacteria in a microfluidic device. PLOS ONE. 14(10), e0222484.

Jousset, A. (2012). Ecological and evolutive implications of bacterial defences against predators. Environmental Microbiology, 14(8):1830-1843.

Jousset, A., Lara, E., Wall, L. G., \& Valverde, C. (2006). Secondary metabolites help biocontrol strain Pseudomonas fluorescens CHA0 to escape protozoan grazing. Applied and Environmental Microbiology. 72(11): 7083-7090.

Jousset, A., Rochat, L., Scheu, S., Bonkowski, M., \& Keel, C. (2010). Predator-prey chemical warfare determines the expression of biocontrol genes by rhizosphere-associated pseudomonas fluorescens. Applied and Environmental Microbiology. 76(15): 5263-5268.

Khan, N. A. (2006). Acanthamoeba: Biology and increasing importance in human health. FEMS Microbiology Reviews. 30(4): 564-595. 
451 Latifi, A., Winson, M. K., Foglino, M., Bycroft, B. W., Stewart, G. S. A. B., Lazdunski, A. \& 452 Williams, P. (1995). Multiple homologues of LuxR and LuxI control expression of virulence 453 determinants and secondary metabolites through quorum sensing in Pseudomonas aeruginosa 454 PAO1. Molecular Microbiology. 17: 333-343.

455 Maddula, V. S. R. K., Pierson, E. A., \& Pierson, L. S. (2008). Altering the ratio of phenazines in 456 Pseudomonas chlororaphis (aureofaciens) strain 30-84: Effects on biofilm formation and 457 pathogen inhibition. Journal of Bacteriology. 190(8): 2759-2766.

458

459

460

461

462

463

464

465

466

467

468

469

470

471

472

473

474

475

476

477

478

479

480

481

Manuel, J., Selin, C., Dilantha Fernando, W. G., \& de Kievit, T. (2012). Stringent response mutants of Pseudomonas chlororaphis PA23 exhibit enhanced antifungal activity against Sclerotinia sclerotiorum in vitro. Microbiology. 158(1): 207-216.

Marciano-Cabral, F., \& Cabral, G. (2003). Acanthamoeba spp. as agents of disease in humans. In Clinical Microbiology Reviews. 16(2): 273-307.

Matz, C., Deines, P., Boenigk, J., Arndt, H., Eberl, L., Kjelleberg, S., \& Jürgens, K. (2004). Impact of Violacein-Producing Bacteria on Survival and Feeding of Bacterivorous Nanoflagellates. Applied and Environmental Microbiology. 70(3): 1593-1599.

Mazzola, M., de Bruijn, I., Cohen, M. F., \& Raaijmakers, J. M. (2009). Protozoan-induced regulation of cyclic lipopeptide biosynthesis is an effective predation defense mechanism for Pseudomonas fluorescens. Applied and Environmental Microbiology. 75(21): 6804-6811.

Miller, J.H. 1972. Assay of $\beta$-galactosidase. Experiments in Molecular Genetics, pp. 352355. Cold Spring Harbor NY, Cold Spring, Harbor Laboratory Press

Moffat, J. F., \& Tompkins, L. S. (1992). A quantitative model of intracellular growth of Legionella pneumophila in Acanthamoeba castellanii. Infection and Immunity. 60(1): 296-301.

Nandi, M., Selin, C., Brassinga, A. K. C., Belmonte, M. F., Fernando, W. G. D., Loewen, P. C., \& de Kievit, T. R. (2015). Pyrrolnitrin and hydrogen cyanide production by Pseudomonas chlororaphis strain PA23 exhibits nematicidal and repellent activity against Caenorhabditis elegans. PLoS ONE. 10(4).

Nandi, M., Selin, C., Brawerman, G., Fernando, W. G. D., \& de Kievit, T. (2017). Hydrogen cyanide, which contributes to Pseudomonas chlororaphis strain PA23 biocontrol, is upregulated in the presence of glycine. Biological Control. 108: 47-54.

Neilson, J. B., Ivey, M. H. \& Bulmer, G. S. 1978. Cryptococcus neoformans: pseudohyphal forms surviving culture with Acanthamoeba polyphaga. Infection and Immunity. 20: 262-266. 
482 Okada, A., Banno, S., Ichiishi, A., Kimura, M., Yamaguchi, I., \& Fujimura, M. (2005). 483 Pyrrolnitrin Interferes with Osmotic Signal Transduction in Neurospora crassa. Journal of 484 Pesticide Science. 30(4): 378-383.

485 Olson, E. \& Richards, J. (1967). Structure of the orange pigment from Pseudomonas 486 aureofaciens. Journal of Organic Chemistry. 32: 2887-2890.

487

488

489

490

491

492

493

494

495

496

497

498

499

500

501

502

503

504

505

506

507

508

509

510

511

512

513

514
Philippot, L., Raaijmakers, J. M., Lemanceau, P., \& van der Putten, W. H. (2013). Going back to the roots: The microbial ecology of the rhizosphere. Nature Reviews Microbiology. 11(11): 789799.

Poritsanos, N., Selin, C., Fernando, W. G. D., Nakkeeran, S., \& de Kievit, T. R. (2006). A GacS deficiency does not affect Pseudomonas chlororaphis PA23 fitness when growing on canola, in aged batch culture or as a biofilm. Canadian Journal of Microbiology. 52(2006): 1177-1188.

Preston, M.J., Seed, P.C., Toder, D.S., Iglewski, B.H., Ohman, D.E., Gustin, J.K., Goldberg, J.B. and Pier, G.B. (1997). Contribution of proteases and LasR to the virulence of Pseudomonas aeruginosa during corneal infections. Infection and Immunity. 65: 3086-3090.

Reimmann, C., Ginet, N., Michel, L., Keel, C., Michaux, P., Krishnapillai, V., Zala, M., Heurlier, K., Triandafillu, K., Harms, H, Défago, G. and Haas, D. (2002). Genetically programmed autoinducer destruction reduces virulence gene expression and swarming motility in Pseudomonas aeruginosa PAO1. Microbiology. 148: 923-932.

Savchuk, S., \& Fernando, W. G. D. (2004). Effect of timing of application and population dynamics on the degree of biological control of Sclerotinia sclerotiorum by bacterial antagonists. FEMS Microbiology Ecology. 49(3): 379-388.

Selin, C., Fernando, W. G. D., \& de Kievit, T. (2012). The PhzI/PhzR quorum-sensing system is required for pyrrolnitrin and phenazine production and exhibits cross-regulation with RpoS in Pseudomonas chlororaphis PA23. Microbiology. 158(4): 896-907.

Selin, C., Habibian, R., Poritsanos, N., Athukorala, S. N. P., Fernando, D., \& de Kievit, T. R. (2010). Phenazines are not essential for Pseudomonas chlororaphis PA23 biocontrol of Sclerotinia sclerotiorum but do play a role in biofilm formation. FEMS Microbiology Ecology. 71(1): 73-83.

Selin, C., Manuel, J., Fernando, W. G. D., \& de Kievit, T. (2014). Expression of the Pseudomonas chlororaphis strain PA23 Rsm system is under control of GacA, RpoS, PsrA, quorum sensing and the stringent response. Biological Control. 69: 24-33.

Steiner, U. K. (2007). Investment in defense and cost of predator-induced defense along a resource gradient. Oecologia. 152(2): 201-210.

Peer) reviewing PDF | (2020:10:53627:1:1:NEW 14 Dec 2020) 
515 Tripathi, R. K., \& Gottlieb, D. (1969). Mechanism of action of the antifungal antibiotic 516 pyrrolnitrin. Journal of Bacteriology. 100(1): 310-318.

517 Zhang, Y., Fernando, W. G. D., Kievit, T. R. de, Berry, C., Daayf, F., \& Paulitz, T. C. (2006). 518 Detection of antibiotic-related genes from bacterial biocontrol agents with polymerase chain 519 reaction. Canadian Journal of Microbiology. 52(5): 476-481.

520 


\section{FIGURE LEGENDS}

522 Figure 1. Growth of Acanthamoeba castellani trophozoites on PA23 and derivative strains in 523 M9-glc. Amoeba growth and viability were monitored for 15 days. Asterisks indicate significant 524 difference from the PA23 WT as determined by two-way ANOVA $(*, P<0.001 ; * *, P<$

525 0.0001). Note: $\mathrm{PHZ}^{-}, \mathrm{PRN}^{-}$and $\mathrm{HCN}^{-}$mutants are statistically significant at day 15 only, whereas

526 the $g a c S^{-}$, AI-deficient, and $p h z R^{-}$strains are statistically significant at days 1, 5, 10 and 15.

527 Experiments were performed three times; one representative data set is shown.

529 Figure 2. Effect of Acanthamoeba castellani trophozoites on the growth of PA23 and derivative 530 strains in M9-glc. Bacteria and amoebae were co-cultured for 15 days, and bacteria were 531 enumerated on days 1, 5, 10 and 15. By day 15 there were no viable bacteria remaining. 532 Asterisks indicate statistical significance of difference using two-way ANOVA (*, P $<0.01 ; * *$, $533 \mathrm{P}<0.001 ; * * *, \mathrm{P}<0.0001)$. Experiments were performed three times; one representative data 534 set is shown.

536 Figure 3. Incubation of Acanthamoeba castellani trophozoites with bacterial cells and cell-free 537 supernatant. PA23 WT cell-free supernatant (A), gac $S^{-}$cell-free supernatant (B), GFP-tagged 538 gac $S^{-}$cells containing WT cell-free supernatant (C), and trophozoites in Ac buffer (D). Red 539 arrows highlight swollen Ac trophozoites, and black arrows indicate Ac cell lysis. Images were 540 captured using a Zeiss Observer Z1 inverted microscope under 40× magnification. Scale bar $=10$ $541 \mu \mathrm{m}$. 
543 Figure 4. Acanthamoeba castellani trophozoites were challenged with PRN (0-10 $\mu \mathrm{g} / \mathrm{ml})(\mathrm{A})$,

$544 \operatorname{PHZ}(0-50 \mu \mathrm{g} / \mathrm{ml})(\mathrm{B})$ and $\mathrm{KCN}(0-800 \mu \mathrm{g} / \mathrm{ml})(\mathrm{C})$. Asterisks indicate statistical significance of 545 difference using two-way ANOVA $(*, \mathrm{P}<0.01 ; * *, \mathrm{P}<0.001)$. Three replicates were used per 546 trial, and the experiment was repeated three times. One representative data set is shown.

548 Figure 5. Chemotactic response of Acanthamoeba castellani towards PA23 WT and derivative 549 strains. (A) Schematic diagram illustrating Petri plate set up. Active amoebae were placed in the 550 center well; the test bacterium was placed in the test well, and PA23 WT, the gacS mutant or 551 saline was added to the control well. Chemotactic preference assays were carried out against 552 saline control (B), PA23 WT (C), and the gacS mutant (D). The chemotactic response was 553 determined as follows: the number of amoebae migrating towards the test well / the number of 554 amoebae migrating towards the control well. Values $>0$ indicated attraction; values $<0$

555 indicated repellent activity. Assays were performed in triplicate and the experiment was repeated 556 three times. Error bars indicate \pm SD; columns labelled with the same letter do not differ 557 significantly by the Tukey test $(\mathrm{P}>0.05)$.

Figure 6. The impact of Acanthamoeba castellani cells and cell free supernatant on prnA, phzA, 560 phzI, phzR, gacS and rpoS expression in Pseudomonas chlororaphis PA23. Co-cultures with Ac trophozoites $(\Delta)$, Ac cell-free supernatant $(\square)$ and bacteria alone $(\bullet)$ were analyzed for $\beta$ galactosidase activity (Miller units) at 24, 48 and $72 \mathrm{~h}$. Asterisks indicate statistical significance of difference using two-way ANOVA $(*, \mathrm{P}<0.01)$. Experiments were performed three times; one representative data set is shown. 
565 Supplemental Figure 1. Bacterial survival in Ac buffer over time. PA23 and derivative strains

566 were grown in Ac buffer and cells were enumerated on day 0, 1, 5, 10 and 15. No viable cells

567 were remaining by day 15 .

568

569 Supplemental Figure 2. Total Acanthamoeba castellani counts showing proportion of live,

570 dead and encysted cells in co-cultures with PA23 and derivative strains. Total counts are

571 expressed as the percentage relative to day 0 , which is set at $100 \%$. 
Figure 1

Growth of Acanthamoeba trophozoites on PA23 and derivative strains in M9-glc.

Amoeba growth and viability were monitored for 15 days. Asterisks indicate significant difference from the PA23 WT as determined by two-way ANOVA $(*, \mathrm{P}<0.001 ; * *, \mathrm{P}<$ 0.0001). Note: $\mathrm{PHZ}^{-}, \mathrm{PRN}^{-}$and $\mathrm{HCN}^{-}$mutants are statistically significant at day 15 only, whereas the gacS, Al-deficient, and phz $R^{-}$strains are statistically significant at days $1,5,10$ and 15. Experiments were performed three times; one representative data set is shown.

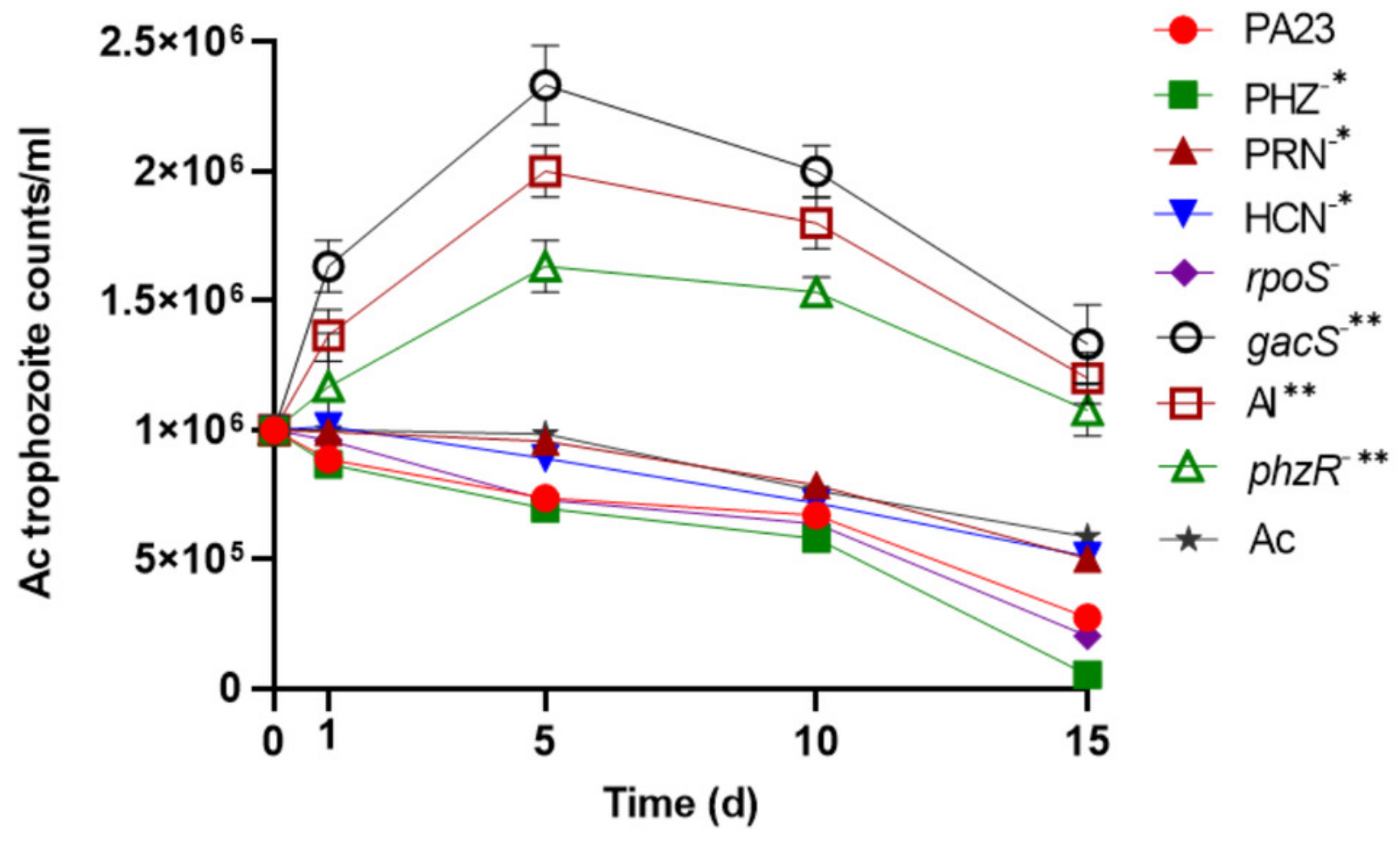


Figure 2

Effect of Acanthamoeba castellani trophozoites on the growth of PA23 and derivative strains in M9-glc.

Bacteria and amoeba were co-cultured for 15 days, and bacteria were enumerated on days 1, 5, 10 and 15. By day 15 there were no viable bacteria remaining. Asterisks indicate statistical significance of difference using two-way ANOVA (*, P $<0.01 ; * *, \mathrm{P}<0.001 ; * * *, \mathrm{P}<0.0001)$. Experiments were performed three times; one representative data set is shown.

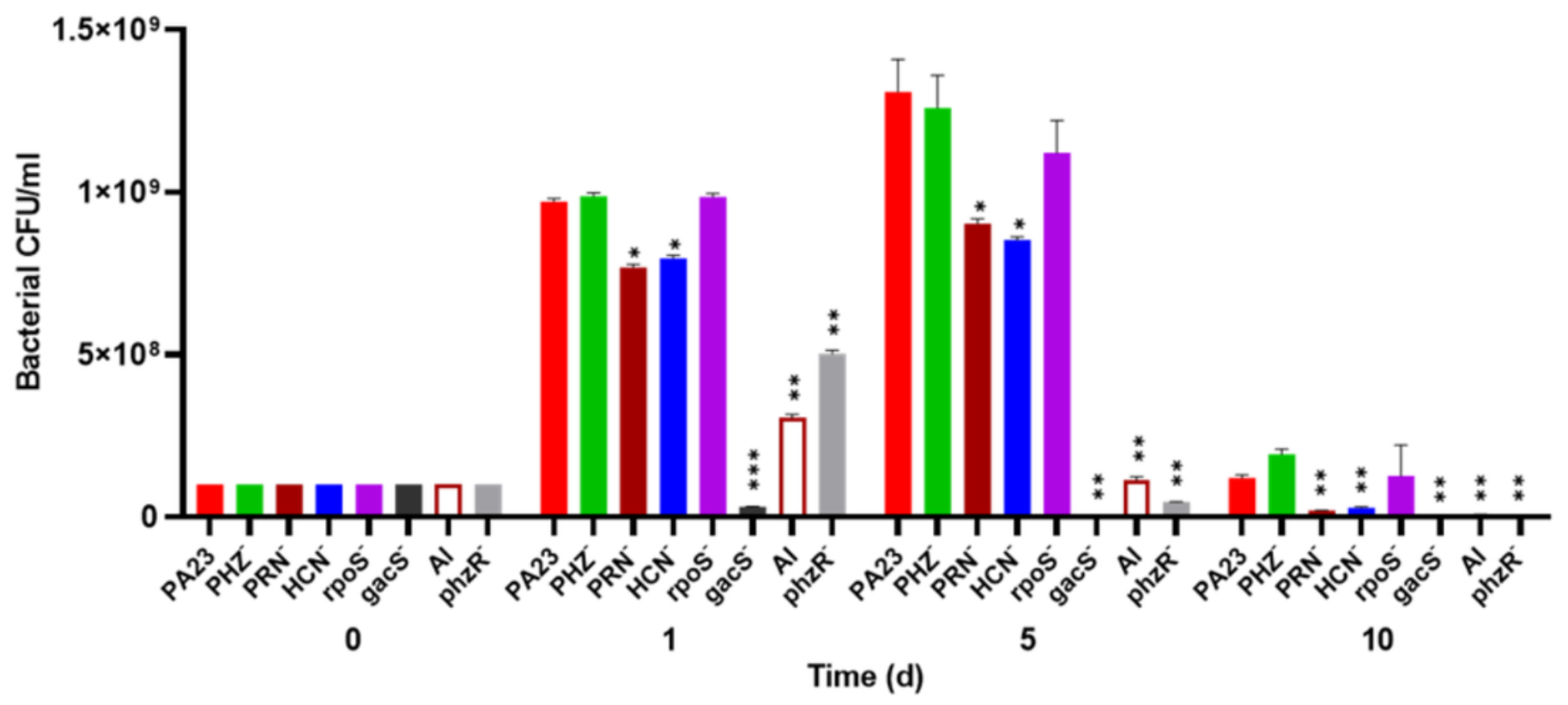


Figure 3

Incubation of Acanthamoeba castellani trophozoites with bacterial cells and cell-free supernatant.

PA23 WT cell-free supernatant (A), gacS- cell-free supernatant (B), GFP-tagged gacS- cells containing WT cell-free supernatant (C), and trophozoites in Ac buffer (D). Red arrows highlight swollen Ac trophozoites, and black arrows indicate Ac cell lysis. Images were captured using a Zeiss Observer Z1 inverted microscope under 40x magnification. Scale bar $=10 \mu \mathrm{m}$. 
PA23 WT cell-free supernatant $+\mathrm{Ac}$

gacS cell-free supernatant $+\mathrm{Ac}$
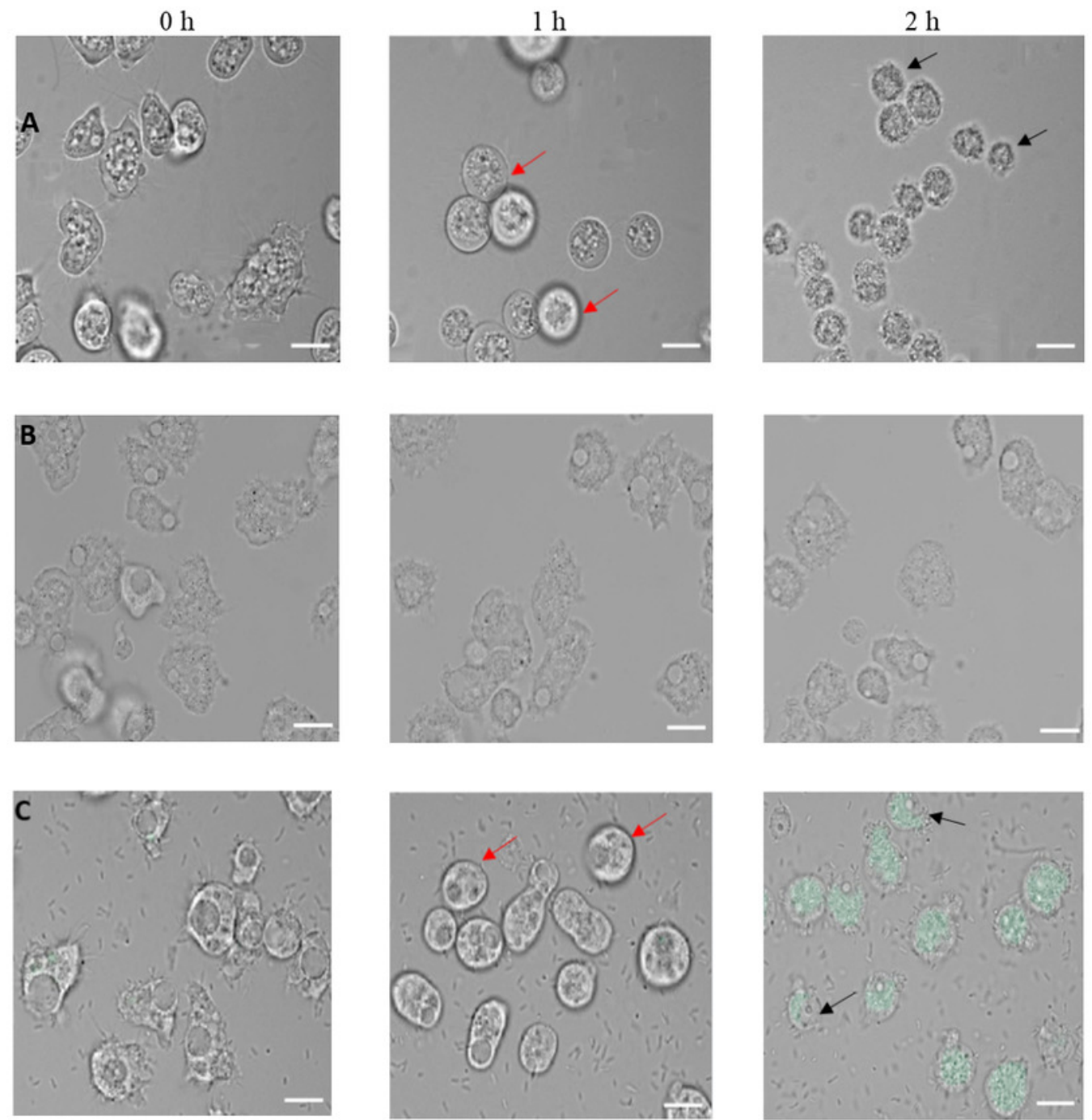

GFP-tagged gacS cells in WT cell-free supernatant $+\mathrm{Ac}$
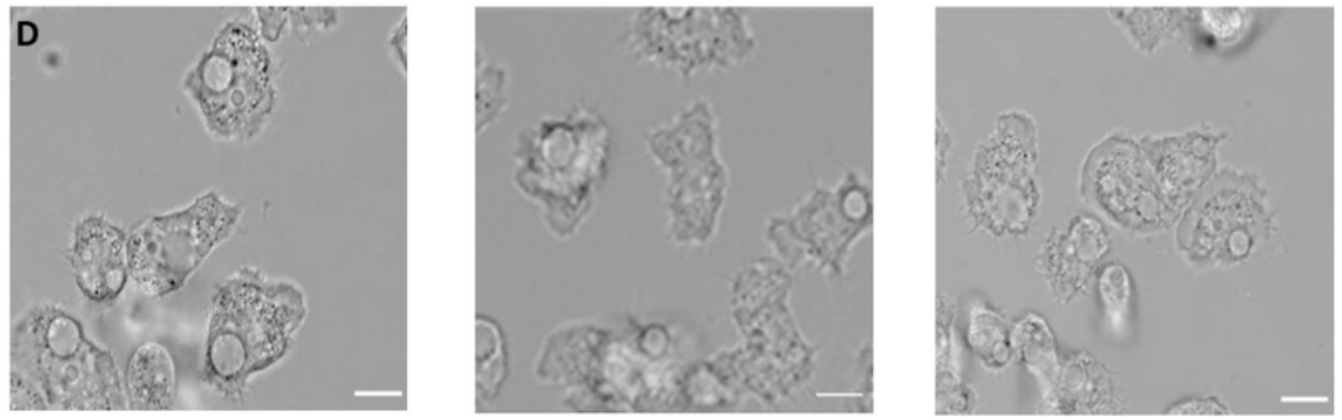


\section{Figure 4}

Acanthamoeba castellani trophozoites challenged with PRN (0-10 $\mu \mathrm{g} / \mathrm{ml})(\mathrm{A}), \mathrm{PHZ}(0-50$ $\mu \mathrm{g} / \mathrm{ml})(\mathrm{B})$ and $\mathrm{KCN}(0-800 \mu \mathrm{g} / \mathrm{ml})(\mathrm{C})$.

Asterisks indicate statistical significance of difference using two-way ANOVA (*, P < 0.01; **, $P<0.001)$. Three replicates were used per trial, and the experiment was repeated three times. One representative data set is shown. 

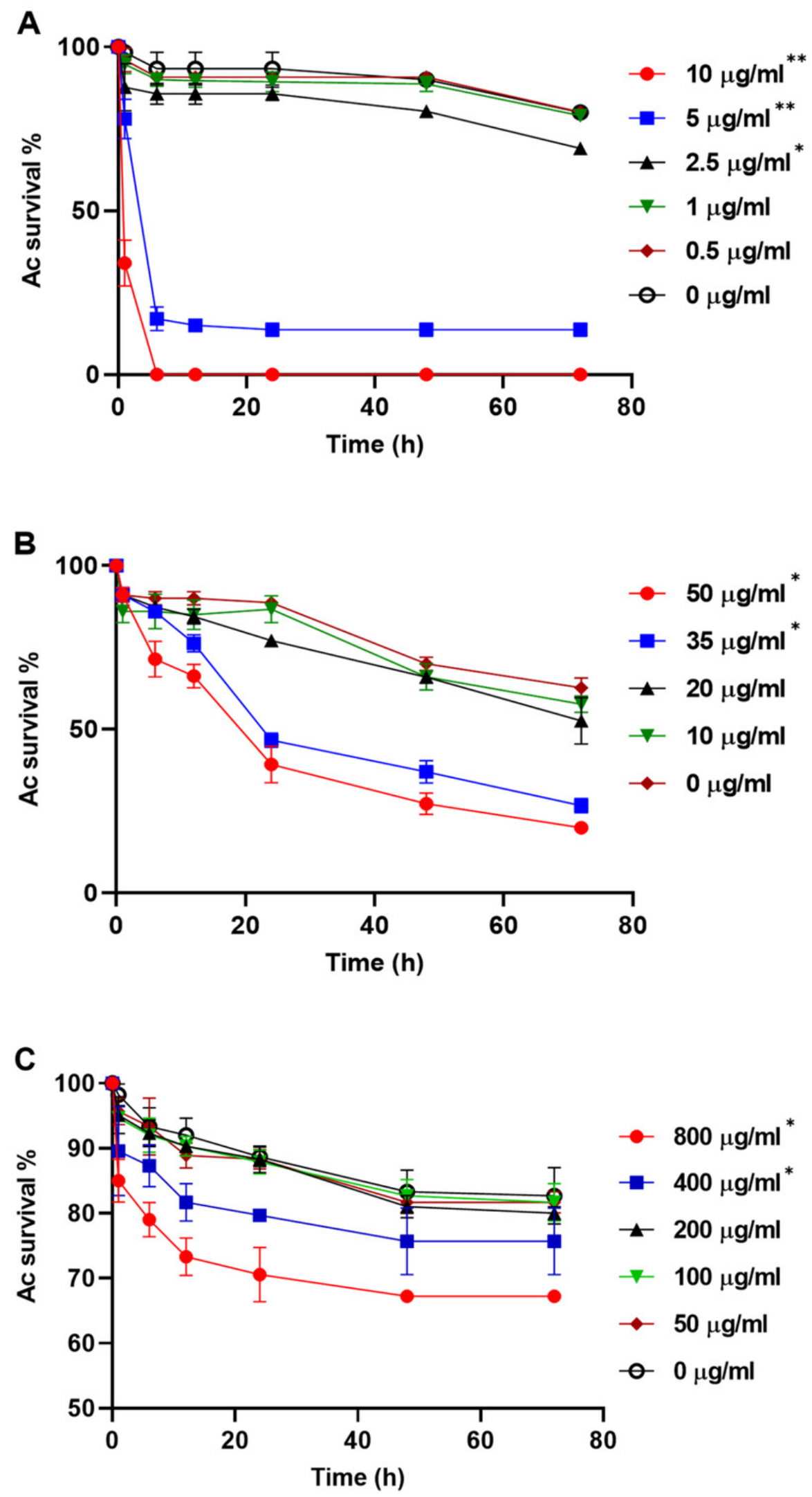


\section{Figure 5}

Chemotactic response of Acanthamoeba castellani towards PA23 WT and derivative strains.

(A) Schematic diagram illustrating Petri plate set up. Active amoebae were placed in the center well; the test bacterium was placed in the test well, and PA23 WT, the gacS mutant or saline was added to the control well. Chemotactic preference assays were carried out against saline control (B), PA23 WT (C), and the gacS mutant (D). The chemotactic response was determined as follows: the number of amoeba migrating towards the test well / the number of amoebae migrating towards the control well. Values $>0$ indicated attraction; values $<0$ indicated repellent activity. Assays were performed in triplicate and the experiment was repeated three times. Error bars indicate $\pm \mathrm{SD}$; columns labelled with the same letter do not differ significantly by the Tukey test $(P>0.05)$. 
A

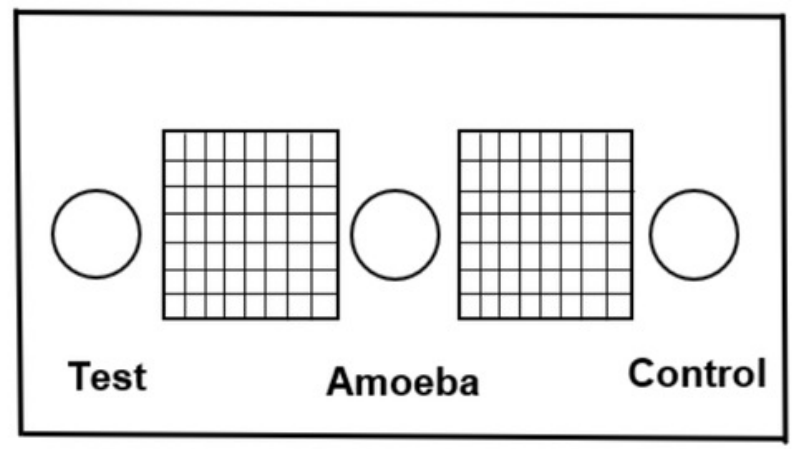

C

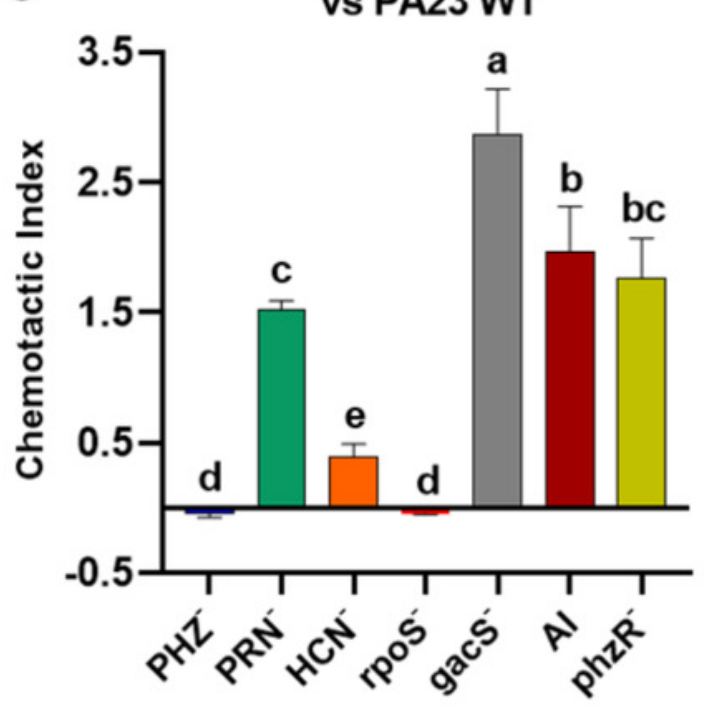

B

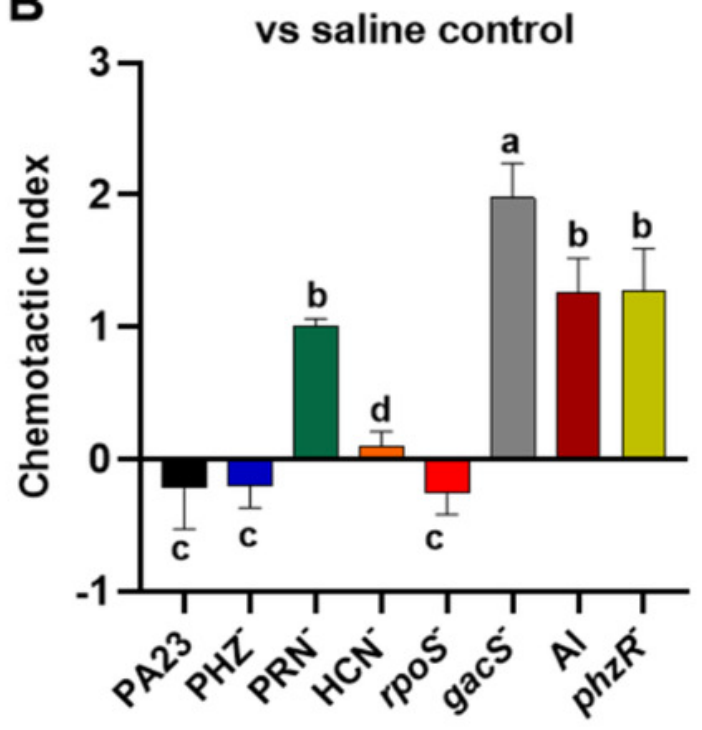

D vs gacs mutant

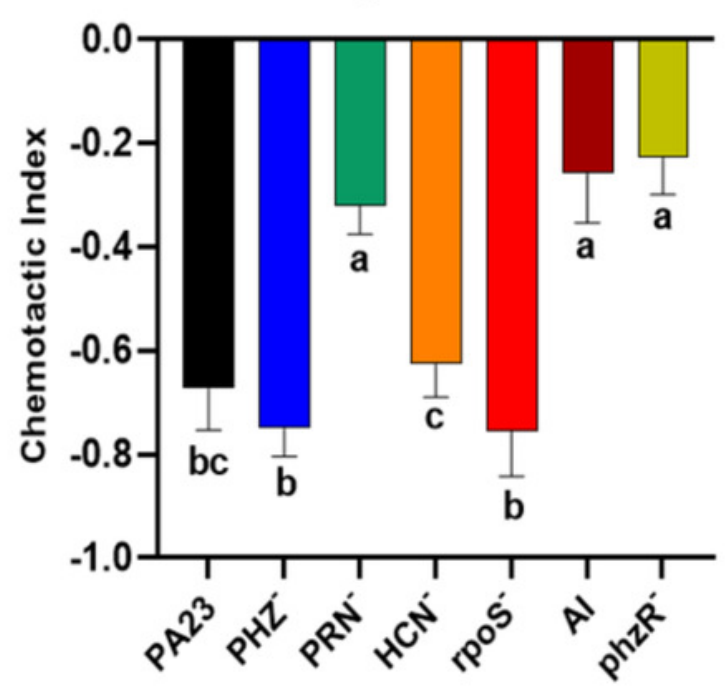




\section{Figure 6}

The impact of Acanthamoeba castellani cells and cell free supernatant on prnA, phzA, phzl, phzR, gacS and rpoS expression in Pseudomonas chlororaphis PA23.

Co-cultures with Ac trophozoites $(\boldsymbol{\Lambda})$, Ac cell-free supernatant $(\boldsymbol{\square})$ and bacteria alone ($(\mathbf{\bullet})$ were analyzed for $\beta$-galactosidase activity (Miller units) at 24, 48 and $72 \mathrm{~h}$. Asterisks indicate statistical significance of difference using two-way ANOVA ( $*, P<0.01)$. Experiments were performed three times; one representative data set is shown. 

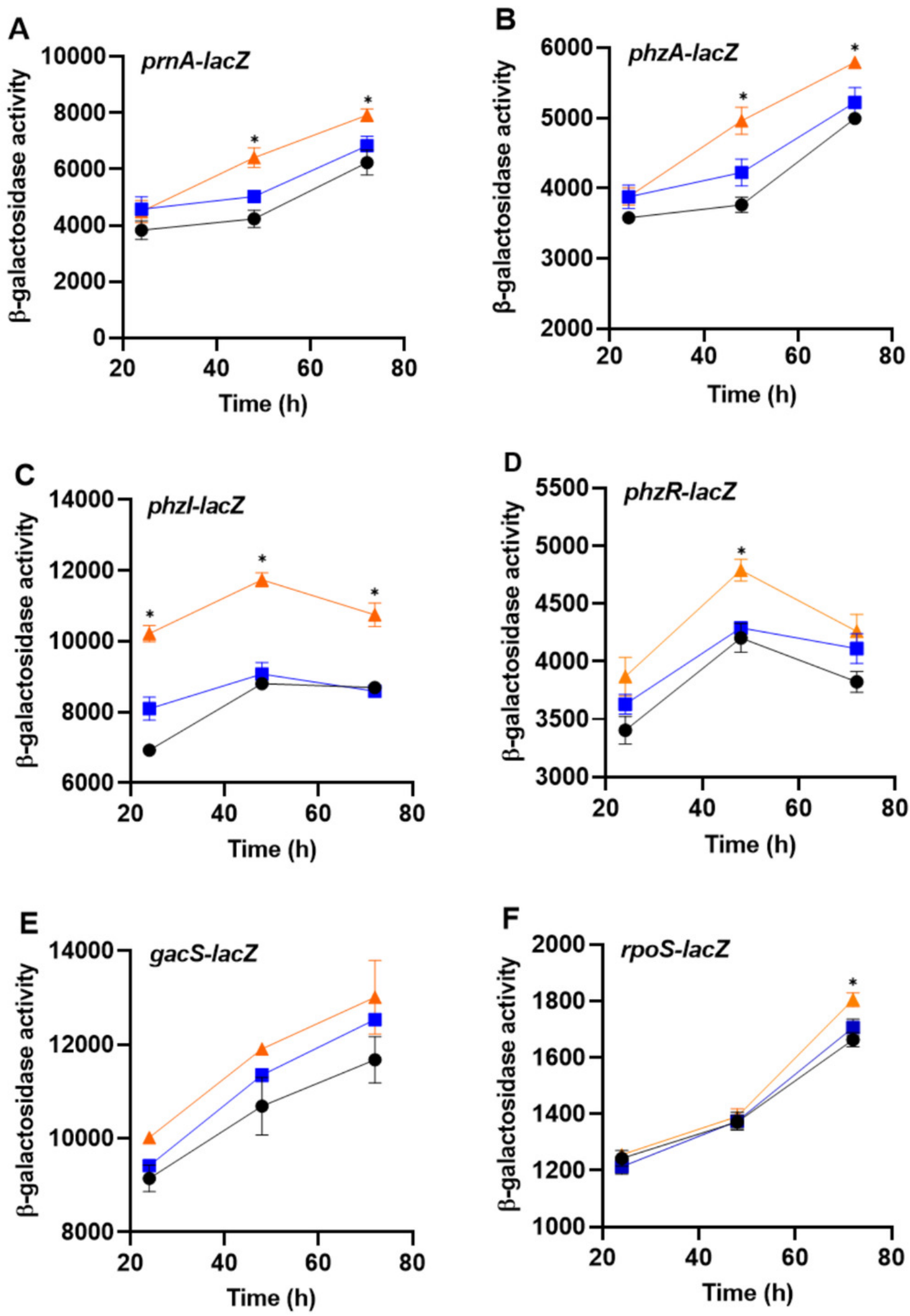


\section{Table $\mathbf{1}$ (on next page)}

Bacterial strains and plasmids used in the study. 
1 Table 1. Bacterial strains and plasmids used in the study.

\begin{tabular}{|c|c|c|}
\hline $\begin{array}{l}\text { Strains, plasmids } \\
\text { \& primers }\end{array}$ & Relevant genotype, phenotype or sequence & Reference or source \\
\hline \multicolumn{3}{|l|}{ Strains } \\
\hline \multicolumn{3}{|l|}{ P. chlororaphis } \\
\hline PA23 & $\begin{array}{l}\text { PRN+PHZ+Rif }{ }^{R} \text {, wild-type (soybean root tip } \\
\text { isolate) }\end{array}$ & $\begin{array}{l}\text { Savchuk \& Fernando } \\
\text { (2004) }\end{array}$ \\
\hline PA23-8 & $\mathrm{PRN}^{-\mathrm{Rif}^{\mathrm{R}}}$ prnBC deletion mutant & Selin et al. (2010) \\
\hline PA23-63 & PHZ-Rif ${ }^{\mathrm{R}} p h z E:$ Tn5-OT182 genomic fusion & Selin et al. (2010) \\
\hline PA23-63-1 & $\begin{array}{l}\text { PRN-PHZ-Rif }{ }^{\mathrm{R}} \text { phzE::Tn5-OT182 genomic } \\
\text { fusion; } p r n B C \text { deletion mutant }\end{array}$ & Selin et al. (2010 \\
\hline PA23hcn & $\begin{array}{l}\text { PA23 with the pKNOCK-Tc vector inserted into } \\
\text { the } h c n \text { gene }\end{array}$ & Nandi et al. (2015) \\
\hline PA23-6863 & PA23 carrying pME6863; AHL deficient & Selin et al. (2012) \\
\hline PA23phzR & PA23 with $\mathrm{Gm}^{\mathrm{R}}$ marker inserted into $p h z R$ gene & Selin et al. (2012) \\
\hline PA23rpos & $\begin{array}{l}\text { PA23 with pKNOCK-Tc vector inserted into } \\
\text { rpoS gene }\end{array}$ & Selin et al. (2012) \\
\hline PA23gacA & $\mathrm{Gm}^{\mathrm{R}}$ marker inserted into the $g a c A$ gene & Selin et al. (2014) \\
\hline PA23-314 & Rif $^{\mathrm{R}}$ gacS::Tn-OT182 genomic fusion & Poritsanos et al. (2006) \\
\hline PA23-gfp & $\begin{array}{l}\text { PA23 containing GFP expressed from pTDK- } \\
\text { GFP }\end{array}$ & This study \\
\hline PA23-8-gfp & $\begin{array}{l}\text { PA23-8 containing GFP expressed from pTDK- } \\
\text { GFP }\end{array}$ & This study \\
\hline PA23-63-gfp & $\begin{array}{l}\text { PA23-63 containing GFP expressed from pTDK- } \\
\text { GFP }\end{array}$ & This study \\
\hline PA23-63-1-gfp & $\begin{array}{l}\text { PA23-63-1 containing GFP expressed from } \\
\text { pTDK-GFP }\end{array}$ & This study \\
\hline PA23hcn-gfp & $\begin{array}{l}\text { PA23hcn containing GFP expressed from } \\
\text { pTDK-GFP }\end{array}$ & This study \\
\hline PA23-6863-gfp & $\begin{array}{l}\text { PA23-6863 containing GFP expressed from } \\
\text { pTDK-GFP }\end{array}$ & This study \\
\hline PA23phzR-gfp & $\begin{array}{l}\text { PA23phzR containing GFP expressed from } \\
\text { pTDK-GFP }\end{array}$ & This study \\
\hline PA23rpos-gfp & $\begin{array}{l}\text { PA23rpoS containing GFP expressed from } \\
\text { pTDK-GFP }\end{array}$ & This study \\
\hline PA23gacS-gfp & $\begin{array}{l}\text { PA23gacS containing GFP expressed from } \\
\text { pTDK-GFP }\end{array}$ & This study \\
\hline
\end{tabular}




\section{Chromobacterium}

violaceum

CVO26 Autoinducer synthase (cviI) mutant from $C$.

Latifi et al. (1995)

Plasmids

pME6863

violaceum ATCC 31532 autoinducer biosensor

pME6000 carrying the aiiA gene from Bacillus

Reimmann et al. sp.A24 under the constitutive $\mathrm{P}_{\text {lac }}$ promoter (2002)

pTdK-GFP

GFPmut3.1 gene under control of the lac promoter, contains an origin of replication for both $P$. aeruginos $a$ and $E$. coli, Amp ${ }^{\mathrm{R}}$

pLP170 lac $Z$ transcriptional fusion vector

de Kievit et al. (2001)

pPRNA-lacZ

prnA promoter in pLP170

Preston et al. (1997)

pPHZA-lacZ

$p h z A$ promoter in pLP170

Selin et al. (2010)

pPHZI-lacZ

phzI promoter in pLP170

Selin et al. (2010)

pPHZR-lacZ

$p h z R$ promoter in $\mathrm{pLP} 170$

Selin et al. (2012)

pRPOS-lacZ

rpoS promoter in $\mathrm{pLP} 170$

Selin et al. (2012)

pGACS-lacZ

gacS promoter in pLP170

Poritsanos et al. (2006)

Nandi et al. (2015) 
Table 2 (on next page)

Phenotypic characterization of PA23 grown in the presence and absence of Ac. 
6 Table 2. Phenotypic characterization of PA23 grown in the presence and absence of Ac.

\begin{tabular}{lcccccc}
\hline Organism & $\begin{array}{c}\text { PHZ } \\
(\boldsymbol{\mu g} / \mathbf{m l})^{\mathbf{a}}\end{array}$ & $\begin{array}{c}\text { PRN } \\
(\boldsymbol{\mu g} / \mathbf{m l})^{\mathbf{a}}\end{array}$ & $\begin{array}{c}\text { Antifungal } \\
(\mathbf{m m})^{\mathbf{b}}\end{array}$ & $\begin{array}{c}\text { Protease } \\
(\mathbf{m m})^{\mathbf{b}}\end{array}$ & $\begin{array}{c}\text { AHL } \\
(\mathbf{m m})^{\mathbf{b}}\end{array}$ & $\begin{array}{c}\text { Motility } \\
(\mathbf{c m})^{\mathbf{b}}\end{array}$ \\
\hline PA23 alone & $32.8(1.4)$ & $3.4(0.3)$ & $5.12(0.6)$ & $4.87(0.2)$ & $4.62(0.4)$ & $59.6(1.2)$ \\
PA23 + Ac & $38.16(0.9)^{*}$ & $4.4(0.3)^{*}$ & $5.25(0.5)$ & $5.25(0.5)$ & $4.62(0.4)$ & $62(0.8)$ \\
\hline
\end{tabular}

7 aMean \pm SD obtained from five replicates.

8 bMean \pm SD of zones of activity obtained from five replicates.

$9{ }^{*}$ Significantly different from PA23 WT $(P<0.05)$. 